\title{
A Case of a Male with Fever and Fatigue
}

Steve Ting

Thomas Jefferson University

Follow this and additional works at: https://jdc.jefferson.edu/tmf

Part of the Allergy and Immunology Commons, and the Infectious Disease Commons Let us know how access to this document benefits you

\section{Recommended Citation}

Ting, Steve (2003) "A Case of a Male with Fever and Fatigue," The Medicine Forum: Vol. 4 , Article 7. DOI: https://doi.org/10.29046/TMF.004.1.008

Available at: https://jdc.jefferson.edu/tmf/vol4/iss1/7

This Article is brought to you for free and open access by the Jefferson Digital Commons. The Jefferson Digital Commons is a service of Thomas Jefferson University's Center for Teaching and Learning (CTL). The Commons is a showcase for Jefferson books and journals, peer-reviewed scholarly publications, unique historical collections from the University archives, and teaching tools. The Jefferson Digital Commons allows researchers and interested readers anywhere in the world to learn about and keep up to date with Jefferson scholarship. This article has been accepted for inclusion in The Medicine Forum by an authorized administrator of the Jefferson Digital Commons. For more information, please contact: JeffersonDigitalCommons@jefferson.edu. 


\section{A Case of a Male with Fever and Fatigue}

Steve Ting, Internal Medicine Resident, PGY3, 2000-2003

This is a case of a 78 year old Caucasian gentleman who presented to the hospital in the early summer with complaints of high fevers and progressive fatigue. The patient lives near Philadelphia and enjoys doing yard work. He reported finding a tick attached to the skin near his groin approximately 3 weeks prior to admission. The tick was removed; however the patient was unsure of the duration of the tick attachment. He also denied developing any significant rash in that area. He had no recent sick contacts and no recent history of travel. He began developing fever spikes up to $39.2 \mathrm{C}$ (102.5 F) associated with chills and sweats. Patient complained of progressive fatigue over the ensuing few days which become so severe he did not even have the energy to walk across the room. He also had generalized muscle aches and a decreased appetite.

He had a past medical history of atrial fibrillation, hypertension, and benign prostatic hypertrophy, but had been in good health until one week prior to admission. His medications included doxazosin, atenolol, and warfarin, none of which were new. He drinks alcohol once or twice a month and quit smoking 40 years ago. He did not have any headaches, visual changes, stiff neck, cough, shortness of breath, nausea, vomiting, abdominal pain, urinary or bowel habit changes.

On admission his temperature was $37.8 \mathrm{C}(100 \mathrm{~F})$ orally, heart rate was 90, and his $\mathrm{BP}$ was 92/63. His room air pulse oximetry was $94 \%$. He appeared somewhat fatigued but was alert, oriented and in no acute distress. Sclera were anicteric. Oral mucosa was dry but had no lesions. Neck was supple without any palpable lymphadenopathy. Heart was irregularly irregular without extra heart sounds. Lungs were clear bilaterally. His abdomen was soft, non-tender, without hepatosplenomegaly. There was no axillary or inguinal lymphadenopathy. His extremities were warm and without edema. Skin examination did not reveal any jaundice or rash.
The patient's initial laboratory data are listed below

\begin{tabular}{l|l}
\hline & Value \\
\hline CBC & \\
\hline WBC & $1600 * / \mathrm{LL}$ \\
\hline Hemoglobin & $13.9 \mathrm{mg} / \mathrm{dL}$ \\
\hline Platelets & $6100 / \mathrm{uL}$ \\
\hline Chemistries & \\
\hline Sodium & $126 \mathrm{meq} / \mathrm{L}$ \\
\hline Potassium & $4.6 \mathrm{meq} / \mathrm{L}$ \\
\hline Bicarbonate & $23 \mathrm{meq} / \mathrm{L}$ \\
\hline BUN & $27 \mathrm{mg} / \mathrm{dL}$ \\
\hline Creatinine & $1.2 \mathrm{mg} / \mathrm{dL}$ \\
\hline Glucose & $104 \mathrm{mg} / \mathrm{dL}$ \\
\hline Hepatic Panel & \\
\hline Total protein & $5.7 \mathrm{~g} / \mathrm{dL}$ \\
\hline Albumin & $3.7 \mathrm{~g} / \mathrm{dL}$ \\
\hline Total Bilirubin & $1.2 \mathrm{mg} / \mathrm{dL}$ \\
\hline AST & $159 \mathrm{u} / \mathrm{L}$ \\
\hline ALT & $68 \mathrm{u} / \mathrm{L}$ \\
\hline Alk. Phosphatase & $91 \mathrm{u} / \mathrm{L}$ \\
\hline Coagulation & \\
\hline Prothrombin time & $26.9 \mathrm{sec}$ \\
\hline aPTT & $70 \mathrm{sec}$ \\
\hline D-dimer & $2 \mathrm{ug} / \mathrm{mL}$ \\
\hline * Differential was $85 \%$ neutrophils, $11 \% \mathrm{lymphocytes,3 \%} 3 \%$ \\
monocytes &
\end{tabular}

\section{Hospital Course}

The patient was admitted to the hospital. Given the patient's history, a tick borne disease was suspected. The high fever, non-specific symptoms, leukopenia, thrombocytopenia, elevated transaminases, and lack of rash suggested ehrlichosis. He was started on doxycycline and was volume repleted with isotonic saline with improvement of his blood pressure. Within the first 48 hours of hospitalization the patient's fever subsided and he demonstrated a remarkable improvement in energy level and reduction in symptoms. Over the ensuing few days his WBC increased to 5.2 and his platelet count increased to 90 . His serum transaminases also returned to a normal level. The peripheral blood smear was examined and demonstrated many atypical lymphocytes, but no intracellular morulae were seen. Nevertheless, his presentation and clinical response was convincing for ehrlichiosis. Given his clinical improvement and his normalizing laboratory values, the patient was discharged home to complete a 3 week course of doxycycline. Several days after discharge, an ehrlichiosis antibody that had been collected on admission returned positive. 


\section{Discussion}

Ehrlichial organisms are obligate intracellular bacteria that can cause two forms of disease seen in humans, human monocytic ehrlichiosis (HME) and human granulocytic ehrlichiosis (HGE). HME is caused by $\mathrm{E}$. chaffeensis which is carried by the Lone Star Tick (Amblyomma americanum) and HGE is caused by a E. phagocytophila or E. ewingii, which can be transmitted by the Lone Star Tick or the Deer Tick Ixodes Scapularis, the same tick that can transmit Lyme and Babesiosis. The main animal hosts are white tail deer and the whitefooted mouse. HME mainly occurs in the southern and mid-Atlantic regions of the US, although cases have also occurred in the New England area. HGE occurs mostly in the northeastern US or the upper Midwest states. Most cases of ehrlichiosis occur in the spring or summer.

The incubation time is about one to two weeks. Ehrlichiosis is usually an acute febrile illness accompanied by non-specific symptoms of headache, malaise, arthralgias, myalgias and occasionally nausea or vomiting. In contrast to Lyme disease, rash is not a predominant feature of this disease. In HME, only about one-third of patients will develop a rash, which can be maculopapular or petechial. Rash is even less common in HGE, occurring in only about $5 \%$ of cases.

Laboratory values are helpful with the diagnosis of ehrlichiosis. The most common findings are leukopenia and thrombocytopenia. The peripheral blood smear can show atypical lymphocytes. Elevated plasma aminotransferases are also commonly found. These abnormal values usually return to baseline after treatment.

There are several ways to diagnose ehrlichiosis. Examination of the peripheral blood smear often demonstrates the presence of atypical lymphocytes and the presence of inclusion bodies inside the cytoplasm of white blood cells called morulae (see figure below). When seen, these morulae are very characteristic of ehrlichiosis but they are only present in about $40-50 \%$ of cases of HGE and only about 5-15\% of cases of HME. Indirect immunofluorescence is used to detect antibodies against ehrlichial antigens with a minimum titer of 1:64 required for diagnosis. Although PCR has not yet become standard, it has potential to become an excellent tool for diagnosis. Ehrlichial species are notoriously difficult to grow in blood cultures.

Tetracyclines are used in the treatment of ehrlichiosis, although this is based on empirical data as there are no well-designed, randomized, placebo controlled trials involving antimicrobial therapy. The general recommendations are for treatment with doxycycline for two weeks (100mg po bid), although some sources recommend treatment until five days after defervescence. Response to treatment usually occurs in about $24-48$ hours.

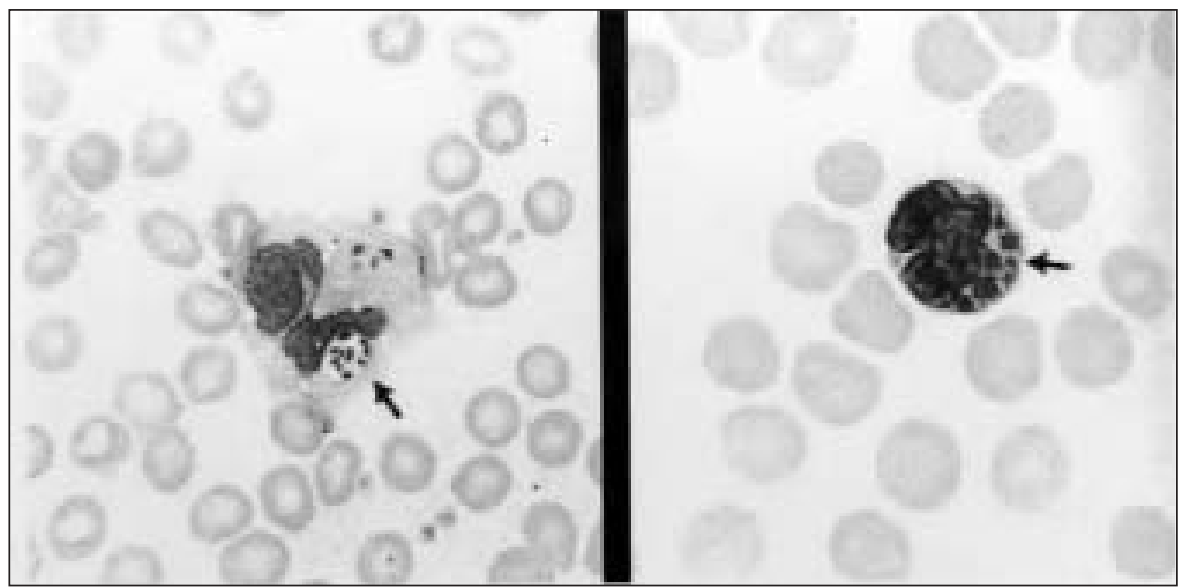

The peripheral smear on the right demonstrates intracytoplasmic Ehrlichia chaffeensis morulae. the smear on the left shows loosely packed morulae within a vacuole of a leukocyte. Images taken from: Martin GS, et al. N Engl J Med 1999; 341:764. 